1 DECISION-MAKING BIASES IN ANIMALS: A CRITICAL REVIEW

Julia Watzek ${ }^{* 1}$, Sarah F. Brosnan ${ }^{1,2}$

${ }^{1}$ Department of Psychology, Language Research Center, Georgia State University, Atlanta, GA, USA

${ }^{2}$ Department of Philosophy, Neuroscience Institute, Center for Behavioral

Neuroscience, Georgia State University, Atlanta, GA, USA

*Correspondence

11 Julia Watzek

12 Email: j.watzek@gmail.com

13 ORCID: 0000-0002-9150-7469

\title{
Funding
}

17 This work was supported by National Science Foundation (NSF) grants

18 SES 1123897 and SES 1425216 (to SFB), and the Duane M. Rumbaugh

19 Fellowship from Georgia State University (to JW).

Conflicts of Interest/Competing Interests

22 The authors declare that they have no conflicts of interest.

Authors' Contributions

JW and SFB wrote and revised the paper.

cknowledgements

28 Water jar icon in Figure 2 was made by Freepik

29 (https://www.flaticon.com/authors/freepik).

\section{Ethics Approval}

Not applicable

Consent to Participate/Consent for Publication

Not applicable

\section{Data and Code Availability}

Not applicable 


\section{ABSTRACT}

41 Humans make thousands of decisions every day, and in some situations, we make reliably bad ones. Much research has explored the circumstances in which such irrational decision-making occurs, but the underlying mechanisms are often unclear. One approach that has recently gained traction is to study other species' responses to similar scenarios to better understand our own decision-making strategies. Here we provide a critical discussion of experimental studies of decision-making biases in animals. We begin by demonstrating how comparative research can yield unique insights into our own decision-making that cannot be gained from studying humans alone. In particular, while comparative research helps us better understand how and why decision-making biases have evolved and which mechanisms underlie them, such studies often overlook how these behaviors vary, both within and between individuals. Methodological concerns and a lack in the diversity of species studied and the number of animals tested complicate this issue and can limit the inferences we can draw. We emphasize the need to study why and when some animals would be expected to show these biases while others would not. Further, rather than just assess whether a given bias is present, comparative research should measure the extent to which it is. We argue that studying how susceptibility to biases varies both within and between individuals is crucial to better understanding the nature of irrational decision-making. We suggest practical steps that open up exciting avenues for future comparative research in this area. psychology

Keywords: decision-making, cognitive bias, rationality, comparative

\section{INTRODUCTION}

Good decision-making is critical to the everyday lives of humans and animals alike. For animals, bad decisions can easily result in death or reproductive failure; for humans, in dire financial straits or toxic relationships. But what makes for a good decision? How can we evaluate decision-making objectively? Traditional economics provides benchmarks for optimal strategies in different situations (e.g., rational choice theory: von Neumann and Morgenstern 2007). Such theories typically assume that decision-makers have full information and the ability to use it. As a result, rational decision-makers should form stable and absolute preferences.

77 However, we rarely do so in the real world. We are frequently influenced

78 by factors that - according to such normative theories - should not matter 
(e.g., how a question is worded), and, as a result, we make consistently suboptimal decisions in certain situations. Our preferences can change based on how options are presented and which ones are available, on who else is watching or what they receive, or on what might have been (nudge theory: Thaler 1980, 1992, 2016; Kahneman et al. 1982; e.g., behavioral game theory: Camerer 2003; prospect theory: Kahneman 2011). Although it is now well known that we often do not behave rationally, there is no unified framework that explains when or how we fail to do so either. This issue is complicated because it is not always clear what behavior counts as irrational in the first place. For example, some perspectives define rationality in relation to a species' cognitive system and environmental conditions rather than in relation to traditional economic principles (Kacelnik 2006; e.g., bounded rationality: Camerer 1998; Gigerenzer and Brighton 2009; Gigerenzer and Goldstein 1996; Gigerenzer and Selten 2001; Gigerenzer and Todd 1999; ecological or biological rationality: De Petrillo and Rosati 2019; Stevens 2012; The Modelling Animal Decisions

95 Group et al. 2014).

Irrational tendencies can lead to paradoxical behavior with realworld consequences. For example, we prefer a longer and more painful sequences if the pain tapers off, are less happy if we have more options, and reject free, no-strings-attached money if we see the situation as unfair (Camerer 2003; Redelmeier et al. 2003; Scheibehenne et al. 2010; Chernev et al. 2015). Of course, other people are not immune to these biases either, and their decisions can deeply impact our lives as well. For example, marketing strategies can affect how much money you spend on a travel package, and countries' policies can affect whether you become an organ donor or whether your child picks healthy foods in the cafeteria (Johnson and Goldstein 2004; Thaler and Sunstein 2009; Hanks et al. 2012; e.g., Cadario and Chandon 2019). Such irrational tendencies can also affect cornerstones of democracy and branches of government, e.g., when the wording on the ballot affects your votes, or when how well a judge slept or when they last ate affects your court case (Bütler and Maréchal 2007; Danziger et al. 2011; e.g., Burnett and Kogan 2015; Eren and Mocan 2016; Cho et al. 2017).

Given the wide-spread and dramatic consequences that decisionmaking biases can have on our lives, it is important to understand why we fall for them. If we want to make better decisions, we need to know why and under what circumstances we make bad ones. This is true for individual decision-makers, but it is particularly important for policymakers to recognize that humans are not always rational. From this knowledge, they should responsibly design decision contexts that elicit 
our inherent values and preferences without distorting them. However, because humans operate in complex physical and social environments in the real world, there are often multiple possible explanations for what causes our decision-making to go awry. For example, problem-solving skills and strategies may be rooted in biological predispositions and may be expressed differently depending on the cultural environment and may change over development. These influences are not mutually exclusive. Therefore, disentangling their role in bad decision-making is crucial because they have different implications for how to address them in order to lead to better choices. One approach to this problem is to study decision-making in other species, which not only gives us model systems free of many of these other influences but also helps clarify the evolutionary history of these decision-making behaviors, which can help us understand their potential function in solving problems we encounter in our environments. Incidentally, a better understanding of bad decisionmaking may also yield a better understanding of good decision-making, because the same psychological processes are likely involved.

In this paper, we demonstrate how studying decision-making biases in other species can help us better understand their evolutionary roots and their underlying mechanisms. We discuss several decisionmaking biases to demonstrate 1) what comparative studies can tell us, 2) what challenges comparative researchers face, and 3) where we can go from here.

\section{INSIGHTS FROM STUDIES OF ANIMAL DECISION-MAKING}

\section{BIASES}

\section{The comparative approach}

Comparing the behavior of multiple species, including humans, is the only way to systematically assess both similarities and differences in how we make decisions. Doing so is vital to understanding how these behaviors have evolved, which mechanisms are at work, and under which circumstances they might have been adaptive. This is important not just for good decisions that we make but particularly for bad ones, because they can be costly both for the individual and for society as a whole. Understanding such decision-making biases from an evolutionary perspective is advantageous if we want to predict when they occur and learn how to overcome them. 
Similarities in the behavior of different species can result from two processes - homology and convergent evolution (Lorenz 1958; Rendall and Di Fiore 2007; Ereshefsky 2007). Behavior is homologous if it occurs in species that share a common ancestor who behaved in the same way. As a result, phylogenetically closely related species may behave more similarly than more distantly related species. For example, dominance patterns may be homologous among primates (Rajecki and Flanery 2013), suggesting that dominance may have been adaptive for the primate common ancestor, for example, as a response to social conflict. However, through convergent evolution, similar behavior can also arise in distantly related species, not due to common descent, but in response to the same selection pressure. Such cases can be particularly informative because the similarities in the ecologies of the species that show a given behavior can help generate hypotheses about its function and adaptive value. For example, inhibitory skills in primate species covary with the degree of fission-fusion dynamics (a form of social complexity in which primate groups split into and merge from variable subgroups) rather than with phylogenetic history. Specifically, apes do not categorically perform better than monkeys, suggesting that inhibitory control may have conferred an evolutionary advantage in potentially risky social interactions (Amici et al. 2008).

Importantly, although multiple species may show similar outcomes and a behavior can even serve the same function, it may arise from different psychological processes. For example, in a two-player coordination game, humans and rhesus macaques adopted a rewardmaximizing strategy that led to nearly identical overall payouts, but people did so by matching their (simulated) partners whereas the monkeys developed a preference for the option that paid well most of the time (Brosnan et al. 2012b; Parrish et al. 2014). Comparative studies provide a unique way to constrain hypotheses about these underlying mechanisms. If other animals show similar behavior to humans, we can conclude that psychological processes unique to humans, such as human language, culture, or experience with financial institutions are not necessary for it to arise or may not affect how the behavior is expressed. Conversely, if we see a given behavior only in a specific species or group of species (e.g., only in humans or only in cetaceans), we can focus on the cognitive processes that may be specific to those organisms. Thus, although each species and population is subject to unique ecological influences, we can hone in on what causes a given behavior by examining the pattern across species through convergent research. 
In this way, much comparative research has established areas in which we are indeed unique as well as areas in which we are not (Fig. 1). For example, humans are unrivaled in our ability to innovate by transmitting and building on the knowledge of previous generations, to work with others in teams comprising thousands of people spanning the globe, and to use these abilities to go to space and uncover the mysteries of the universe. But animals other than humans certainly also use tools (Sanz et al. 2013), cooperate at sometimes large scales (Dugatkin 1997), and show some forms of culture (Laland and Galef 2009). Thus, comparative research often shows that the difference between us and other animals may be one of degree rather than kind. Of course, different species often express behaviors differently (e.g., behaviors that involve extensive use of language in humans), but the degree to which we share them with other species provides distinct insights into how and why they

212 make both good and bad decisions.

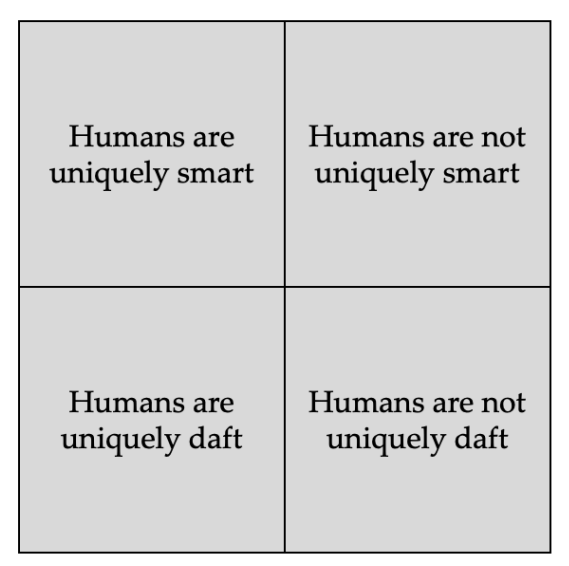

Fig. 1 A simple $2 \times 2$ classification for human decision-making phenomena in comparison to animals

Distinguishing between abilities that we share with other animals and those we do not also provides a unique perspective into how to improve our decision-making approaches. For example, if ant colonies can find the optimal strategy in complex problems through simple individuallevel heuristics, then humans may not need computationally intensive algorithms to solve similar problems either. Ants effectively and efficiently self-organize along lanes on their trails to adjust to heavier traffic, avoiding traffic jams but actually achieving greater speeds at higher traffic densities (Hönicke et al. 2015). These findings may help us 
develop improved traffic control measures that do not necessarily require complicated equipment and flow algorithms. Other endeavors, like colonizing the solar system, of course, rely to a large extent on humanunique abilities (e.g., human language), technologies (e.g., computers), and institutions (e.g., markets), and will need to optimize these aspects in order to succeed.

\section{Mechanisms underlying decision-making biases}

Using the comparative approach to study biases in decisionmaking can tell us whether humans are also uniquely daft in some situations or whether we share some of these irrational tendencies with other animals (Fig. 1). Similar to drawing this distinction for exceptional abilities, thinking about bad decision-making in comparison to other animals can lead to different implications for how to fix it. If only humans show a given bias, we may focus on tweaking human-unique features, such as aspects of digital communication, our financial institutions, or our education systems to elicit better decision-making. On the other hand, if other species show similar behavior, we know that it does not require human-unique mechanisms and can instead consider the role of more widely shared processes.

This rationale has been used to demonstrate, for example, that other animals like birds (Marsh and Kacelnik 2002) and monkeys (Lakshminarayanan et al. 2011) show framing effects - accepting more risk when outcomes are presented as losses than when the same outcomes are presented as gains. Similarly, comparative research found that apes and monkeys show the endowment effect - the tendency to overvalue items we own - in some situations (Brosnan et al. 2007, 2012a; Lakshminaryanan et al. 2008; Kanngiesser et al. 2011; Flemming et al. 2012; Drayton et al. 2013). These results challenge the idea that these hallmark economic decision-making biases (Kahneman and Tversky 1979; Kahneman et al. 1991, 2008; Knetsch 2000) are unique to humans and have to rely on, for example, interactions with formal economic markets. Consequently, both good and bad decisions may often result from simpler cognitive rules than previously recognized.

Of course, that does not necessarily mean that human-unique mechanisms play no role at all, both because several mechanisms may be involved and because the same outcomes may arise from different mechanisms. For example, the endowment effect in animals seems to be limited to food or tools that can be used immediately to obtain it (Brosnan 
et al. 2007, 2012a). Thus, human psychological processes are not necessary for endowment effects to arise, but they may explain why humans show it in broader contexts. Importantly, these differences in how widely the effect is expressed has prompted new inquiries into whether the "evolutionary salience" of the item may explain the variation we see in humans as well (Jones and Brosnan 2008), highlighting that comparative research can yield unique perspectives and testable predictions about human decision-making behavior.

One key feature of most decision-making biases that is obscured in all of these discussions (and our inferential statistics) is the often significant variability seen across individuals within species. Addressing this issue is important to assessing the stability of decision-making biases. Most basically, understanding this variability will help to clarify how different contexts influence decision-making, particularly if the same individuals respond differently across contexts. Moreover, different individuals may respond differently to the same context, suggesting that personality or preference may influence decisions. Here we discuss new research on the sunk cost effect and cognitive set bias and highlight that the extent to which animals show a given bias may vary not just across species but also across individuals or within individuals across trials or sessions. For further demonstrations of the comparative approach in the study of other decision-making phenomena, see reviews by Rosati and Stevens (2009), Santos and Chen (2009), Santos and Rosati (2015), Zentall $(2016,2019)$, and Williamson et al. (2019).

\section{Sunk cost effect}

Humans frequently take prior investments into account when making decisions. This susceptibility to irrecoverable sunk costs is irrational because we should only consider the future expected costs and benefits when making a decision. If you get more from selling your car than not selling it (e.g., because of running costs), you should sell it, regardless of how much you bought it for. People and organizations alike tend to persist in an endeavor to a greater extent the more resources (e.g., time, money, or energy) we have already invested (Arkes and Blumer 1985; Arkes and Ayton 1999), and this can lead to bad decisions. For example, the sunk cost effect may exacerbate a country's economic losses, cause a scientist to waste time on a doomed project, or make you finish (and later regret) a meal when you are already full. Indeed, this bias is sometimes called the Concorde fallacy, after the Concorde airplane project 
that wasted millions in funding even after it had become clear that it was a "commercial disaster" (Central Policy Review Staff 1971).

There are several possible explanations for this phenomenon, none of which are mutually exclusive, making it even trickier to tease them apart. People may rationalize their earlier decisions as sound rather than mistaken in order to justify continued investment (Staw and Fox 1977; Staw and Ross 1989; Staw and Hoàng 1995), may strive to avoid waste (Arkes and Blumer 1985; Arkes 1996; Arkes and Ayton 1999; Arkes and Hutzel 2000), may persevere until they are more certain of the outcome (Bragger et al. 1998; Navarro and Fantino 2005), or may shun a definite large loss (if they cut their losses) when a small additional investment may - but may not! - turn things around with a large gain (Kahneman and Tversky 1979; Thaler 1980; Tversky and Kahneman 1981). However, disentangling these theories empirically has been difficult because they make similar predictions - that the sunk cost effect increases with the size of the sunk cost.

The comparative approach presents one way to address this issue and to better understand the cognitive mechanisms underlying the sunkcost effect. To the extent that human language and culture underlies tendencies such as self-justification and waste avoidance, these explanations would not predict a susceptibility to sunk costs in animals. On the other hand, if, for example, a more universal response to resource scarcity underlies waste avoidance in humans, then we would expect to find some evidence of the sunk cost effect in other animals as well. Similarly, uncertainty reduction and loss aversion, which do not rely on such human-unique factors, could account for sunk cost effects in animals. In fact, testing the effect in multiple animal species may help disentangle these possibilities even further if species differ in whether or how they express these behaviors. For example, to date, only starlings and capuchin monkeys have shown a human-like reflection effect by becoming more risk prone when prospects were framed as losses compared to the same prospects framed as gains (Marsh and Kacelnik 2002; Lakshminarayanan et al. 2011), although, to our knowledge, no other species have been tested in these paradigms. To the extent that the sunk cost effect arises as a result of loss aversion, we would expect it to emerge in species that overvalue losses in this way. Conversely, if loss aversion does not covary with the sunk cost effect, this suggests that it is not a major factor in making the bias emerge, including in humans.

Several animal species have now shown sunk cost effects both in the field and in the laboratory (Magalhães and White 2016). Ecological studies have mainly focused on parental investment in birds to assess 
whether sunk costs affect at what point parents stop raising the current offspring and start investing in the next. In line with the sunk cost effect, parents' nest defense behavior increases the more they have already invested (Weatherhead 1979; Dawkins and Brockmann 1980). However, because parental investments are often indicative of brood value, it is unclear to what extent the future costs and benefits - which should be taken into account - rather than sunk costs - which should not be taking into account - can explain these findings.

In the laboratory, where these factors are more easily controlled, pigeons and rats also show consistent sunk cost effects. They are more likely to complete a reinforcement schedule (rather than abandon it) the more pecks or lever presses they have already completed (Navarro and Fantino 2005; Macaskill and Hackenberg 2012; Magalhães et al. 2012). For example, pigeons completed one of four random fixed ratio schedules, where the schedule that required the fewest pecks was the most common (Navarro and Fantino 2005). Importantly, pigeons could opt out and skip to the next trial at any point by pecking the escape key. In this situation, you should peck for the minimum number of times and escape if that does not yield a reward, i.e., when one of the three longer schedules is in effect. This is the optimal response because, on average, completing the longer trials takes more pecks than starting a new, most likely short trial. However, three out of four pigeons persisted in almost all trials and failed to use the escape key. This effect disappeared when the cost of persisting was increased (i.e., when the longer schedules required many more additional pecks) and when the change in reward schedule was signaled (i.e., when the key changed color when the minimum number of pecks was completed). These results suggest that continued investment may, in part, arise from uncertainty about when it becomes more beneficial to quit than to continue, particularly if the cost to continue is small.

More recently, rats and mice have also shown sunk cost effects when they needed to wait rather than act repeatedly in order to persist (Sweis et al. 2018). In this clever design, the rodents foraged for four different reward options by moving around a testing area with separate compartments. In each room, they could choose whether to move to the next room or whether to accept a waiting time for a reward (the duration was signaled through sounds of varying pitch to remove uncertainty). If they accepted an offer by entering the wait zone of the room, the countdown began, and the rodents received a food pellet if they waited until the end of the countdown. Once again, they could leave at any time during the waiting period but would forfeit the reward and the work (waiting) that they had already committed. Optimally, you should finish 
all trials that you are willing to commit to; otherwise, you should simply opt out and consider a different offer. Consequently, if you commit to a waiting time, then the time that you have already spent waiting (i.e., sunk costs) should not affect whether you will wait until the end. That is, if you commit to waiting for 10 seconds, you should be just as likely to finish the trial when the wait time just started and when you have waited 9 seconds and only have 1 second left. However, in line with the sunk cost effect, rats and mice were more likely to finish a trial the longer they had already waited (Sweis et al. 2018).

Unexpectedly, this effect did not depend on the time that rodents
spent making their initial choice about whether or not to commit, even though it also detracted from the rodents' total time budget. Thus, decisions about continued investment may arise from two different evaluation processes - an initial one involved in opting in or out of an investment and a secondary one involved in whether to continue investing. Only the latter process may be susceptible to sunk costs. Not only does this study demonstrate that animals can show sunk cost effects even when information uncertainty and the need for automated motor responses (such as pecking or lever pressing) are removed, but it highlights how studies of animal decision-making can generate novel hypotheses about human behavior as well. Indeed, the authors tested human participants using a similar procedure, in which they "foraged" for four categories of video clips and were shown a "download bar" that indicated the wait times. Humans showed the same pattern of results; they were more likely to wait until the end the longer they had already waited, but this was unaffected by how long they initially took to decide whether to "download" the video (Sweis et al. 2018).

These findings suggest that very distantly related species share our susceptibility to sunk costs in some situations. This bias therefore does not require tendencies to self-justify or to avoid waste, which are arguably unique to humans. Uncertainty about the remaining effort also cannot explain this behavior, because the wait times were signaled (through sounds) both in the offer and wait zones. While several cognitive mechanisms may be at play, it is informative that widely shared and likely evolutionarily ancient processes can be sufficient. One possibility is that animals rely on heuristics that use past investments as a proxy for future benefits or that increase the perceived value of the reward with increased effort and therefore increased energetic depletion. In other words, the cupcake seems better (and worth waiting longer for) the hungrier you get. In this way, comparative research can constrain our hypotheses about the 
cognitive mechanisms that underlie decision-making biases in cases in which humans are not uniquely daft (Fig. 1).

\section{Cognitive set bias}

One way we navigate complex environments with limited and imperfect information is by taking past investments into account, as illustrated by sunk cost effects. Another way we deal with this problem is by relying on learned rules, which often save us time and cognitive resources because we know what has worked in the past. This strategy is particularly useful if we are likely to encounter the same problem again. Of course, humans and animals alike make decisions in many different situations and those situations change over time. When the context for a decision changes, our learned rules of thumb can become inefficient or altogether ineffective. It is important for us to recognize when familiar rules may no longer work and to adopt alternative strategies that are more beneficial in these situations. However, if we are too receptive to new possibilities, we risk making bad decisions because we get distracted by irrelevant information. For example, a foraging animal may starve if it is unable to adapt to shifting environments; yet if foraging habits are too flexible, it may frequently consume novel and potentially poisonous food items. Thus, optimal behavior requires a balance between exploiting known solutions and exploring alternatives.

Humans are creatures of habit in this respect. For example, in the classic water jar task, participants had to measure out specific amounts of water using three water jars of different sizes (Luchins 1942). Participants had to complete practice problems in which they were "given" three water jars that could each hold a fixed amount of water and had to fill and empty them to measure out a target quantity (Fig. 2). After completing several problems that could be solved by a single, multi-step rule (fill Jar $B$, then pour water from it to fill Jar A once and Jar C twice), people were given critical problems that could also be solved using a simpler rule (fill Jar A and pour water into Jar C once). Participants overwhelmingly persisted in using the longer solution. Humans have since shown this cognitive set, or Einstellung, bias - the tendency for a learned approach to block the use of a better alternative - in a variety of task designs (Duncker 1945; Luchins and Luchins 1950; Aftanas and Koppenaal 1962; Sweller et al. 1982; Ruscio and Amabile 1999; Arrington and Logan 2004; Chrysikou and Weisberg 2005; Bilalić et al. 2008b, a; Crooks and McNeil 2009; ErEl and Meiran 2011; Thomas and Didierjean 2016). 
The Water Jar Task
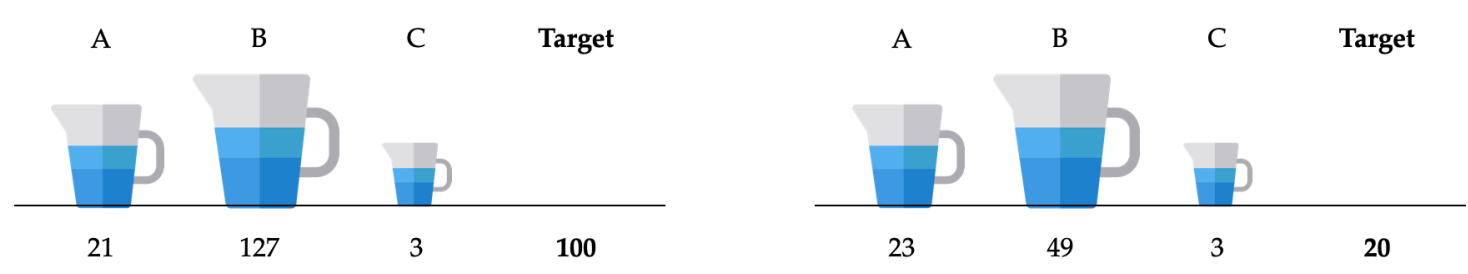

The LS-DS Task

Demo

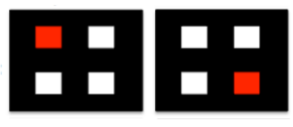

Learned Strategy (LS)
Demo

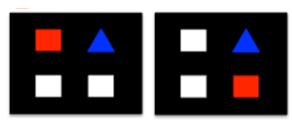

Direct Strategy (DS)

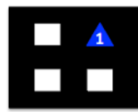

Fig. 2 Schematics of the water jar problem (Luchins 1942) and the LS-DS task (Pope et al. 2015). In practice problems (left), participants learn to reach the target through a multi-step sequence. In probe trials (right), they can still use the familiar strategy, but could instead also use a more efficient shortcut

Interestingly, other primates do not seem to share this cognitive inflexibility. In one nonverbal adaptation using a computer task (Fig. 2; Pope et al. 2015), participants are trained to select three shapes in sequence (Square 1, Square 2, Triangle). Once they are proficient at this learned strategy, they encounter probe trials in which the final shape is present from trial start. Participants can use this more efficient shortcut, but, similar to the water jar problem, the familiar three-step strategy can also be used. In this task, most humans once again stick with the learned strategy, whereas all monkey and ape species tested to date readily abandon the familiar strategy in favor of the shortcut (Pope et al. 2015, 2019; Watzek et al. 2019). These findings narrow down the possible mechanisms underlying cognitive set bias. The humans may have perceived the stimuli and the sequence globally, whereas the apes and monkeys perceived them locally (Fagot and Tomonaga 1999; Spinozzi et al. 2003; De Lillo et al. 2005). However, in a cross-cultural study testing the seminomadic Himba of Namibia with the same nonverbal paradigm, local 490 shortcut use (Pope et al. 2018). 
The Himba used the shortcut more than the Westerners, however, suggesting that cultural influences may shape how people conceptualize a problem and how flexibly they try to solve it. For example, formal schooling in Western cultures may encourage blind repetition and build an expectation that each problem has a single correct solution (Star and Seifert 2006). Indeed, when Westerners were prompted to "try something new," they did just as well as the Himba (Pope et al. 2018; see also Luchins 1942) and Western children used the shortcut more than Western adults (Pope et al. 2015). Thus, differences in how people conceptualize the problem and in what they think they "should do" likely play a role, but this does not explain everything. More than half the adults from both cultures still failed to use the shortcut, whereas none of the baboons or chimpanzees kept using the familiar strategy.

One possibility for why other primates use the more efficient shortcut more than humans is that it requires less working memory. If following the learned strategy is difficult, there is more benefit in seeking out a less effortful alternative (Beilock and DeCaro 2007). Thus, ironically, because the learned rule is easier for humans to learn (as indicated by the lower amount of training) and apply (as indicated by their higher accuracy), we might stick with it more even when a shortcut becomes available. In support of this point, other primates show somewhat more habitual strategy use (by starting with the first step in the sequence but taking the shortcut before completing the full sequence) among a primate species with reportedly high working memory capacity (Pope et al. 2019) and when the learned rule requires less working memory (Watzek et al. 2019). But having fewer cognitive constraints does not explain well why humans show such limited flexibility in this task. The ease with which humans learn and apply the learned strategy hints at yet another candidate explanation - because we can verbally encode the rule, we learn it quickly and it may become more firmly rooted. This allows us to use the rule with high accuracy but may require more cognitive effort to switch to alternative strategies. Indeed, when humans did use the shortcut, they made more mistakes when they had to switch between strategies, whereas monkeys showed no such switch costs (Watzek et al. 2019).

However, while the difference between humans and other primates is stark and robust, there are also differences within each population. Some humans did use the shortcut in all of these studies, some monkeys and apes used the switch strategy, and individuals varied in the extent to which they showed either of the possible strategies. What underlies these interindividual differences in habitual rule use and their willingness to explore alternative strategies is an open question. Further, children used 
the shortcut more than adults, suggesting that we sometimes become less, not more, rational with experience (see also Williamson et al. 2019). And when humans were given additional test trials, more participants eventually started using the shortcut (Watzek et al. 2019). These results highlight both that individual participants may not show the population's average behavior and that a given participant's behavior may not reflect how they behave at all times. Although this point is hardly worldshattering, we argue that comparative research should study this variability explicitly and develop theories about its roots rather than simply treat it as noise.

This research on cognitive set bias provides a nice illustration of how comparative, developmental, and cross-cultural studies can triangulate the psychological mechanisms that underlie decision-making biases - here in an area in which humans seem to be uniquely daft. We showed how testing different species can tell us more than studying humans alone, in the same way that testing children can tell us more than studying adults alone and testing people with a different cultural background can tell us more than studying Westerners alone (e.g., Nielsen and Haun 2016). By comparing these different populations that vary in unique ways, e.g., in their perceptual processing, their cognitive abilities and constraints, their educational history and how they conceptualize problems, and their encoding modes, we can disentangle the role of these different factors in explaining our susceptibility to decision-making biases.

\section{Evolution of decision-making biases}

More than just eliminating or highlighting human-unique mechanisms that may underlie a given bias, the pattern of species that do or do not show it can tell us about its evolutionary history. Biases that are shared widely across the animal kingdom suggest that the proximate cause is evolutionarily ancient. Biases that are shared narrowly across one phylogenetic branch suggest a mechanism common to that group alone (e.g., primates only), and biases found sporadically across different branches suggest a stronger impact of species' ecologies than shared evolutionary history.

To give an example of how this works, humans will routinely forgo or reject rewards if they are distributed unequally among people. Although cultures vary in their aversion to inequity (Henrich et al. 2001), this behavior is often seen as an indicator of the human sense of fairness. A wide array of animal taxa also respond negatively to unequal outcomes, 
although responding when one gets more than a partner is far less common, both within and among species, than responding when one gets less than the partner (for reviews, see Brosnan and de Waal 2014; Oberliessen and Kalenscher 2019). Interestingly, species that cooperate even outside of mating and kinship bonds typically exhibit inequity aversion, whereas related species that do not cooperate (or not as widely) typically do not. Phylogenetic relatedness alone cannot account for this pattern. One proposed explanation is that inequity aversion evolved to maintain equitable cooperative partnerships and to prevent exploitation in these species (Brosnan and de Waal 2014). Of course, there are likely both phylogenetic and ecological factors at play. For example, one form of inequity aversion - responding negatively to receiving more than another - has only been reported in any form in chimpanzees (Brosnan et al. 2010; Proctor et al. 2013), and is by no means ubiquitous (Jensen et al. 2007; Kaiser et al. 2012). Thus, cognitive processes that may only be shared with humans' closest living relatives, such as perhaps greater levels of selfcontrol or anticipatory abilities, may be required to object not just to getting less, but also to getting more than others.

An evolutionary perspective also highlights the importance of considering both the social and physical environments that decision rules have evolved in. A strategy can be adaptive in one context but maladaptive in another, and even closely related species might have social or feeding ecologies that present them with different selection pressures that may, in turn, give rise to different behavioral strategies to cope with them. For example, highly social corvid and lemur species, who may need specific cognitive abilities to navigate more complex social environments, show greater reasoning skills than closely related but less social species (Bond et al. 2003; MacLean et al. 2008).

Differences in feeding ecology can result in similar patterns, for instance in the discounting behavior and risk preferences of primate species. Marmosets are willing to wait for a large reward longer than tamarins, but tamarins are willing to travel farther for it than marmosets (Stevens et al. 2005a, b). Although the two species are closely related, this difference in temporal versus spatial discounting makes sense given the marmosets' reliance on gum and sap, which requires self-control (i.e., waiting for the sap to ooze from a cut in the tree), and the tamarins' reliance on insects, which are ephemeral and require more travel. Similarly, among our two closest living relatives, bonobos, who rely on relatively consistent food sources, are more risk averse whereas chimpanzees, who feed on ephemeral and more highly contested food sources, are more risk prone (Heilbronner et al. 2008). 
Such comparative research may further challenge assumptions of a scala naturae. Not only are humans not at "the top," neither are primates, mammals in general, or, for that matter, anyone. For example, when presented with an ephemeral food source that goes away and a permanent one that is always available, cleaner fish optimize by eating the ephemeral first and then the permanent one, much like they service visiting client reef fish before resident fish in the wild (Bshary and Grutter 2002; Salwiczek et al. 2012). Primates, rats, and pigeons, however, fail to follow this strategy that yields twice as much food in this simple task (grey parrots succeed; for a detailed review, see Zentall 2019), although highlighting cues relevant to primates leads to them demonstrating the same behavioral outcomes as the fish (Prétôt et al. 2016a, b). These results emphasize that animal decision-making needs to be evaluated against species' natural environments. We need to discard the notion that some animals are generally smarter than others because we may not always test them in species-appropriate ways and because, ultimately, the best decision-makers are the ones who solve problems that they actually encounter.

Even within a given species, the context therefore often matters (Rosati and Stevens 2009). For example, chimpanzees show endowment effects for food but not objects (toys; Brosnan et al. 2007), unless the objects are immediately useful to obtain food (Brosnan et al. 2012a), suggesting that the tendency to overvalue objects in one's possession may have evolved for salient items, like food, that have significant effects on fitness. Indeed, in the absence of formalized rules for trade, exchanges are risky, and thus a bird in the hand may well be worth two in the bush. That is, you should value important items that you already have more than those you might get - but might not! Moreover, this tendency may generalize to situations when the risk from exchanges is minimized or removed, as in these experimental tasks. Similarly, organisms may change their risk preferences based on their energetic state, taking on more risks to avoid starvation even if it theoretically pays less in the long run (e.g., Caraco 1981; Dener et al. 2016). Such results can highlight contexts in which irrational behavior might be adaptive and therefore how it may have evolved. Humans, too, may be particularly tuned into specific problems we encounter in everyday life, such as social interactions. For example, people have a hard time with a classic logic puzzle when it is presented in abstract terms but tend to solve it when it is presented as a social exchange (Cosmides and Tooby 1992).

Importantly, when we consider the environments in which decision rules have evolved, seemingly irrational behavior may not look so bad 
after all. In addition, situations in which we violate economic principles of rationality in the laboratory might happen only rarely in the real world. Nonsocial birds do not need to reason about transitive dominance hierarchies and tamarins do not need self-control to wait for sap to exude. If our irrational tendencies rarely lead to errors and are of little consequence when they do, then they cost us very little. But then why follow strategies that are sometimes irrational at all? In some cases, a short-term loss might yield a long-term gain, e.g., if forgoing an unequal reward now results in a more equitable cooperative partnership overall. In other cases, we benefit from following rules of thumb because they save us the time and effort that would be required to always find optimal solutions, especially if there is little to gain from doing so (e.g., Watzek and Brosnan 2018). Such heuristics are useful because our brains' computational power is limited, and if these heuristics fit our environment well enough, they lead to good decision-making most of the time. Thus, decision-making strategies that seem economically irrational may make more sense in the context of our cognitive constraints (bounded rationality: e.g., Camerer 1998; Gigerenzer and Brighton 2009; Gigerenzer and Goldstein 1996; Gigerenzer and Selten 2001; Gigerenzer and Todd 673 biological rationality: e.g., Kacelnik 2006; Stevens 2012; The Modelling

674 Animal Decisions Group et al. 2014; De Petrillo and Rosati 2019).

\section{BIASES}

\section{The importance of truly comparative methodologies}

Although studying decision-making biases in other animals offers unique insights, comparative studies also present unique problems. If we want to draw valid inferences by comparing different species (or different populations within a species), we need valid comparisons. Otherwise, it is unclear whether mixed results within the same species reflect a failure to replicate or simply differences in methodologies (Tomasello and Call 2011; Smith et al. 2018). For example, comparative studies of the peak-end effect - the tendency to overvalue sequences with higher peak values and more positive events at the end - in rhesus macaques find opposite results. Three macaques consistently preferred to receive a higher valued food first and a lower valued food last (contrary to the peak-end effect) in a manual task (Xu et al. 2011), but three macaques from a different laboratory did prefer to "save the best for last" in a computer task in which they chose sequences of juice servings (Blanchard et al. 2014). 
There are many methodological differences between the two studies that may have affected the monkeys' responses. The manual task involved fewer trials ( 30 test trials per session) than the computer task (thousands of training and test trials), used sequences of two rewards that differed in quality (e.g., a grape and half a green bean) rather than quantity, and were much larger than the sequences of five juice rewards (identical, but ranged in quantity from 0.08 to just $0.2 \mathrm{ml}$ for the entire sequence). In addition, the time between items in the manual sequence was longer (several seconds) than in the computer task (always half a second). And while both tasks used two-choice paradigms, the manual task had monkeys choose between a decreasing and an increasing order for the same rewards, which also remained the same throughout testing. The computer task gave monkeys a probe sequence and had them choose whether to repeat it or receive one of several pre-trained comparator sequences, and both sequences varied across trials. Consequently, some possibilities for why the peak-end effect emerged in the computer but not in the manual task are that it might develop through repeated experience, only arises when rewards are small or vary in quantity but not quality, only arises when sequences are almost continuous rather than discrete, or perhaps only comes into effect when limited working memory or other cognitive constraints require the use of a shortcut (for example when comparing sequences of five rewards each that differ only by small amounts). Further, it is not clear how robust these findings are, given that both studies only tested three monkeys (and they did not always show consistent behavior in the manual task, Xu et al., 2011; though there was no statistical effect of monkey identity in the computer task on overall performance, Blanchard et al., 2014).

A study on capuchin monkeys' susceptibility to the peak-end effect (Egan Brad et al. 2016) helps to disentangle these possibilities. In each trial of a manual task, capuchin monkeys chose to trade tokens in exchange for biscuit sticks that were partly covered in frosting (i.e., sections that were preferable to biscuit alone). The biscuit sticks were fed through a little hole, resulting in continuous eating episodes for the monkeys. Other aspects of the procedure similar to Xu and colleagues' manual task (e.g., fairly low trial numbers, large and qualitatively different rewards, rewards remained the same across trials). Two of four capuchins preferred to trade with the experimenter who fed them the frosted end last rather than first (in line with the peak-end effect). These results suggest that, in monkeys, the peak-end bias may only affect evaluations of nearcontinuous sequences of events. However, because each of the three studies used vastly different methods, direct comparisons are limited and 
734

735

736

737

738

739

740

741

742

743

744

745

746

747

748

749

750

751

752

753

754

755

756

757

758

759

760

761

762

763

764

765

766

767

768

769

770

771

772

773

774

future research is needed to determine the extent to which these results generalize.

Even within the same individuals, housing conditions or small adjustments, such as in the length of an inter-trial interval, can make a bias "disappear." Species as distantly related as pigeons, dogs, monkeys, and apes all prefer a high value food by itself to the same food and a low value food, e.g., choosing "cheese alone" over "cheese plus carrot" (for a review, see Zentall 2019). However, this less-is-more or selective-value effect disappears when pigeons in the same laboratory were deprived of food (Zentall et al. 2014) or when the same chimpanzees had longer intervals between trials (Beran et al. 2009b), indicating that experimental factors affect choice behavior through food motivation and expectations about what food will be available in the future.

Of course, these issues make comparisons of decision-making biases between species especially problematic. This effect is compounded if the task itself must be adjusted to take into account differences between the species (e.g., monkeys can indicate a choice by grabbing objects with their hands, but birds might use their beaks, and spiders may choose where to walk their entire bodies, the latter of which functionally disallows attempts to get both objects at once, which may affect bimanual species' choices) or if the comparison is between humans and any other species (see below). If two species are tested on different paradigms and one species shows the effect but another does not, it is difficult, if not impossible, to tell whether this indicates true species differences. Was the task easier for one species due to innate differences in how they interacted with it? Was the adapted task easier, perhaps by providing more cues or additional pretraining? Did the humans get verbal instruction or was the task oversimplified for the other species in an effort to make it comprehensible? Similarly, if both species show the effect or both do not, it is unclear whether the difference in methodology masks species differences that are actually there. If these challenges sound familiar, they are the same ones faced by developmental scientists adapting their tasks for younger and younger children or cross-cultural researchers making sure that their tasks are interpreted in the same ways across many diverse perspectives. It may be even harder for comparative scientists (and infant researchers), however, because we cannot even ask the animals what they thought we were doing as a validation.

For example, some studies have found decoy effects in animals - a shift in the preferences between two options simply by adding a third, non-viable option - but findings and methodologies are extremely mixed. Bees show decoy effects when foraging from artificial flowers that vary in 
the effort they require, gray jays do so when foraging from feeding tubes with varying predation risks (Shafir et al. 2002), and rhesus macaques do when discriminating rectangles that differ in size and orientation (Parrish et al. 2015). However, the same rhesus macaques are unaffected by decoy options when choosing between tasks that vary in effort (Parrish et al. 2018) and two other primate studies do not find decoy effects in capuchins (Cohen and Santos 2016) or four great ape species tested with different food choice tasks (Sánchez-Amaro et al. 2019). Given these differences in paradigms, it is difficult to say what is signal and what is noise, making comparisons - and the conclusions we can draw from them - extremely limited.

Comparative researchers need to be particularly aware of this problem when adapting designs from human decision-making studies for use with animals. Whereas humans can provide one-shot decisions after verbal instructions, animals typically complete trials offering the same choice repeatedly and after sometimes extensive training. If animals show the phenomenon, is it equivalent to the humans' behavior? One way to explore this is to repeat the animal version of the task with human participants. For example, capuchin monkeys' risk preferences change depending on whether options are framed as gains or losses in a nonverbal paradigm (Lakshminarayanan et al. 2011). Though seemingly similar to the classic human findings (Kahneman and Tversky 1979), humans do not show this framing effect when tested with a similar procedure to the monkeys (Silberberg et al. 2013). Of course, this could also be because the tasks used with other species are simplistic and artificial, making them challenging to use with humans, who may not be motivated to do well in them. On the other hand, if animals do not show the phenomenon, does that absence indicate a true species difference or would humans also behave differently if tested with the animal paradigm? For example, chimpanzees, unlike humans, acted in a rational, self-interested way in a nonverbal version of the Ultimatum Game often used to assess fairness (Jensen et al. 2007; see also Kaiser et al. 2012). But when humans are tested in a similar paradigm, they maximize, too (Smith and Silberberg 2010). If we want to draw strong conclusions from comparative research, we need to test different species - humans included - using the same or equivalent procedures (although doing so comes with its own difficulties; see also Smith et al. 2018).

Even within the same species or the very same study population, researchers may vary seemingly small factors for practical reasons. For example, different animals may reasonably work for different food rewards because they show different preferences. Even if the same foods 
are used for all animals, different animals will value them differently. Although animals may show similar preferences (e.g., as indicated by the percentage chosen in two-choice trials), the difference in value between options may be quite different (Casey et al. 2013; Schwartz et al. 2016). Of course, this point is especially important when the difference in reward value can affect the behavior of interest (e.g., Beran et al. 2009a; Xu et al. 2011). In general, comparative researchers need to carefully consider whether the choices that animals make actually reveal their underlying preferences or may instead, for example, result from a lack of inhibition. Primates may "prefer" choosing less over more in the ephemeral reward task not because they actually prefer receiving less but because they are unable to inhibit the prepotent response of reaching for a visible food item or because they are averse to the option that sometimes disappears (Prétôt et al. 2016b). Conversely, capuchin monkeys choose to wait for a "larger, later" reward rather than obtain a "smaller, sooner" one in an intertemporal choice task, but may not actually be able to maintain the longer delay, suggesting that this does not truly reflect a choice to wait (Paglieri et al. 2013). Such seemingly minor changes to methodology can affect animals' choices and lead us to conclude that a given decisionmaking bias is present when it is not or that it is not present when it actually is, which can further complicate comparisons across species.

\section{The importance of inter- and intra-individual variability}

Of course, carefully designing our studies with comparable methodologies is necessary but not sufficient if we want reliable, let alone valid results. Comparative research is notorious for small sample sizes and a limited range of species, and this presents a major obstacle to the comparative study of decision-making biases as well. For example, a recent review of primate cognition research published between 2014 and 2019 found that the median sample size across studies and species was 7 individuals and that fewer than $15 \%$ of primate species had been studied, which limits the generalizability of the results (ManyPrimates et al. 2019). One of the reasons why small samples are problematic is because they reduce our power to detect effects that really exist. If a species does not show a given bias or if a replication attempt fails, we do not know whether it is truly not present or whether we simply failed to detect it. Combined with the file-drawer problem - if null results are less likely to be published than statistically significant results - this can distort the literature and stifle scientific progress. 
Oftentimes, we might find null results when there is a lot of individual variability relative to the effect (e.g., a change in mean preference, averaged over individuals). This pattern can make it hard to detect group-level effects and to generalize from the sample to the population. But this variability can be informative, and we lose a lot by averaging over individuals (and sometimes over species). Indeed, for certain effects we should even predict individuals to vary substantially, e.g. for biases that are hypothesized to rely on limited working memory ability or that vary with personality or with an individual's social relationships or their standing in the group. Rather than focusing just on whether a given bias is absent or present on a species level, we should strive to assess the extent to which it is, because individuals may vary in the strength of the effect or some individuals may be susceptible whereas others are not. For example, animals from a variety of species have shown negative responses to inequity (Brosnan and de Waal 2014; Oberliessen and Kalenscher 2019), including chimpanzees. However, in no study to date has this been the case for every single chimpanzee, and factors such as personality and the length of the relationship between partners have been suggested to affect the inequity response (Brosnan et al. 2005, 2010, 2015; Bräuer et al. 2006).

Assessing biases on a continuum rather than on a binary also opens up opportunities to further understand the underlying mechanisms and to assess the effect of different methodologies. For example, whether animals with a certain rank, sex, age, or cognitive skill are more susceptible to a bias helps us tease apart the effect of cognitive constraints, social relationships, and hormonal factors. This is particularly true in situations in which an individual's outcomes depend on what others do, e.g., in tests of cooperation or competition (see, e.g., Watzek et al. 2018). For example, if experimental tests of cooperation in the laboratory rely solely on pairs of animals who are, at a minimum, willing to be in proximity of each other, they likely result in a distorted picture of cooperative behavior because we know that it varies depending on who the partner is and how many animals are involved (e.g., in chimpanzees: Melis et al. 2006a, b; Suchak et al. 2014, 2017). Similarly, if those animals who show an effect in one paradigm also do so in another, then we can be more confident that both paradigms tap into the same underlying concept. Ideally, we can even extend this approach to testing whether different decision-making biases tend to co-occur, to assess the extent to which individual factors play a role. comes from changes over time, e.g., over the course of trials or sessions. 
This can be problematic because decision-making strategies can change also over time, e.g., due to learning effects, order effects, or satiation effects as an animal's energetic state changes with rewards from earlier trials. For example, primates' previous choices can affect their valuation of current options (Egan et al. 2007, 2010; West et al. 2010), and food deprivation might lead animals to make more rational, reward

FUTURE DIRECTIONS FOR STUDIES OF ANIMAL DECISION-

\section{MAKING BIASES} maximizing choices (Zentall et al. 2014) or to take risks they prefer to avoid when satiated (Caraco 1981). Therefore, the assumption that animals' choices in repeated trials are independent may rarely hold true, and we need to systematically assess changes over time. Finally, to our knowledge there are no studies of decision-making biases that assess the stability of these effects over longer time periods. Such studies may be more feasible when working with animals in the laboratory because the same animals can be tested repeatedly.

\section{Comparative research into how animals make good or bad} decisions promises unique insights into our own behavior. By assessing how a phenomenon is distributed across multiple species that vary in their cognitive abilities, constraints, and experiences, we can constrain our hypotheses for the psychological processes that give rise to it. For example, sunk cost effects can clearly arise in the absence of formal economic markets or arguably human-unique tendencies such as waste avoidance, and may rely on more wide-spread cognitive mechanisms. On the other hand, cognitive set bias may be unique to humans and arise from verbal encoding, greater working memory availability, and cultural or educational expectations about how to solve problems.

Further, the patterns in how closely or distantly related the species that share a given effect are can reveal at which points in the phylogenetic tree it evolved. Knowing to what extent behaviors are homologous or convergent, in turn, lets us generate hypotheses about why they may have evolved. Do these decision strategies solve a problem that is commonly encountered in these species' environments? Inequity aversion, for instance, may lead to a short-term loss but ensure better cooperation in the long run. Or are biases simply by-products of otherwise adaptive strategies that fail in certain circumstances? If so, how often do animals actually encounter situations in which such irrational behavior would emerge and how costly is it? Studying decision-making biases in species other than our own lets us answer these questions. Importantly, this 
research can yield insights and new testable predictions that can help better explain human behavior as well. For example, the findings that the strength of endowment effects may vary with the evolutionary salience of the object, and that sunk cost effects may not accrue while weighing whether to invest but only for ongoing investments arose from comparative research but have implications for human decision-making.

However, in order to draw valid evolutionary inferences from cross-species comparisons, we need a reliable and valid body of empirical work. Methodological differences both within and across species, small sample sizes, and limited diversity in the kinds of species that have been tested are major challenges to the comparative study of decision-making biases. If we are not sure whether a given bias is present or not in a specific species, let alone whether the "same" bias was assessed in another species, any inferences that rely on how the phenomenon is distributed across species are severely limited. To complicate this issue, by simply assessing presence or absence, we may miss out on important variability in how strongly an effect manifests and whether it is affected by changes over time (e.g., learning through experience) or reliably predicted by individual differences.

Of course, no single researcher can address all of these issues and gaps in the comparative study of decision-making biases, but neither can they only be solved by top-down changes to the field at large. Practices that individual researchers can adopt range from minimal changes to current procedures to literal and figurative paradigm shifts. Of course, some of these measures will not be possible in every case, e.g., for practical or ethical reasons. Nonetheless, here we list some ideas that individual researcher can adopt themselves in their role as study authors or can encourage others to adopt in their role as reviewers and editors:

1. Conducting direct replications of previous studies in the same species.

2. Testing other populations and study species with the same paradigm used with other species in previous studies.

3. Testing the same study population with several paradigms for the same concept.

4. Collaborating with others to increase sample sizes and ensure direct comparability.

5. Reporting data for individuals and considering potential sources of variability. If possible, sharing raw data on a more detailed level to improve peer review and allow for secondary analyses. 
1004 1005

6. Reporting the extent of biases as dependent variables and design experimental measures to capture a continuum rather than a binary.

7. Publishing results regardless of outcome. Preregistrations and article formats such as registered reports are two recent developments that can help in combatting the file-drawer problem from the researcher side. Of course, increased willingness to recommend and accept "negative" or mixed results by journals is necessary on the reviewer and publisher side.

We believe that the field stands to benefit immensely if comparative researchers adopt even just some of these practices. Doing so helps us build a robust body of scientific literature on both good and bad decision-making in animals. This allows us to more deeply understand how, when, and why we make these decisions than we could by studying humans alone, revealing the cognitive processes and evolutionary forces that give rise to irrational behavior. Combined with insights from developmental and cross-cultural perspectives, such an understanding is crucial to disentangling the factors that influence our own behavior, which, ultimately, will help us make better decisions.

\section{REFERENCES}

Aftanas MS, Koppenaal RJ (1962) Effects of instructional problems and jar position variation on the water-jar Einstellung test. Psychol Rep 10:359-362. https://doi.org/10.2466/pr0.1962.10.2.359

Amici F, Aureli F, Call J (2008) Fission-fusion dynamics, behavioral flexibility, and inhibitory control in primates. Curr Biol 18:14151419. https://doi.org/10.1016/j.cub.2008.08.020

Arkes HR (1996) The psychology of waste. J Behav Decis Mak 9:213-224. https://doi.org/10.1002/(SICI)1099-0771(199609)9:3<213::AIDBDM230>3.0.CO;2-1

Arkes HR, Ayton P (1999) The sunk cost and Concorde effects: Are humans less rational than lower animals? Psychol Bull 125:591-600. https://doi.org/10.1037/0033-2909.125.5.591

Arkes HR, Blumer C (1985) The psychology of sunk cost. Organ Behav Hum Decis Process 35:124-140. https://doi.org/10.1016/07495978(85)90049-4

Arkes HR, Hutzel L (2000) The role of probability of success estimates in the sunk cost effect. J Behav Decis Mak 13:295-306. 
1032

1033

1034

1035

1036

1037

1038

1039

1040

1041

1042

1043

1044

1045

1046

1047

1048

1049

1050

1051

1052

1053

1054

1055

1056

Arrington CM, Logan GD (2004) The cost of a voluntary task switch. Psychol Sci 15:610-615. https://doi.org/10.1111_j.09567976.2004.00728.x

Beilock SL, DeCaro MS (2007) From poor performance to success under stress: Working memory, strategy selection, and mathematical problem solving under pressure. J Exp Psychol Learn Mem Cogn 33:983-998. https://doi.org/10.1037/0278-7393.33.6.983

Beran MJ, Evans TA, Ratliff CL (2009a) Perception of food amounts by chimpanzees (Pan troglodytes): The role of magnitude, contiguity, and wholeness. J Exp Psychol Anim Behav Process 35:516-524. https://doi.org/10.1037/a0015488

Beran MJ, Ratliff CL, Evans TA (2009b) Natural choice in chimpanzees (Pan troglodytes): Perceptual and temporal effects on selective value. Learn Motiv 40:186-196. https://doi.org/10.1016/j.lmot.2008.11.002

Bilalić M, McLeod P, Gobet F (2008a) Why good thoughts block better ones: The mechanism of the pernicious Einstellung (set) effect. Cognition 108:652-661. https://doi.org/10.1016/j.cognition.2008.05.005

Bilalić M, McLeod P, Gobet F (2008b) Inflexibility of experts - reality or myth? Quantifying the Einstellung effect in chess masters. Cognit Psychol 56:73-102. https://doi.org/10.1016/j.cogpsych.2007.02.001

Blanchard TC, Wolfe LS, Vlaev I, et al (2014) Biases in preferences for sequences of outcomes in monkeys. Cognition 130:289-299. https://doi.org/10.1016/j.cognition.2013.11.012

Bond AB, Kamil AC, Balda RP (2003) Social complexity and transitive inference in corvids. Anim Behav 65:479-487. https://doi.org/10.1006/anbe.2003.2101

Bragger JD, Bragger D, Hantula DA, Kirnan J (1998) Hyteresis and uncertainty: The effect of uncertainty on delays to exit decisions. Organ Behav Hum Decis Process 74:229-253. https://doi.org/10.1006/obhd.1998.2779

Bräuer J, Call J, Tomasello M (2006) Are apes really inequity averse? Proc R Soc B Biol Sci 273:3123-3128. https://doi.org/10.1098/rspb.2006.3693

Brosnan SF, de Waal FBM (2014) Evolution of responses to (un)fairness. Science 346:1251776-1251776. https://doi.org/10.1126/science.1251776

Brosnan SF, Hopper LM, Richey S, et al (2015) Personality influences responses to inequity and contrast in chimpanzees. Anim Behav 101:75-87. https://doi.org/10.1016/j.anbehav.2014.12.019 
1057

1058

1059

1060

1061

1062

1063

1064

1065

1066

1067

1068

1069

1070

1071

1072

1073

1074

1075

1076

1077

1078

1079

1080

1081

1082

1083

1084

1085

1086

1087

1088

1089

1090

1091

1092

1093

1094

1095

1096

Brosnan SF, Jones OD, Gardner M, et al (2012a) Evolution and the expression of biases: Situational value changes the endowment effect in chimpanzees. Evol Hum Behav 33:378-386. https://doi.org/10.1016/j.evolhumbehav.2011.11.009

Brosnan SF, Jones OD, Lambeth SP, et al (2007) Endowment effects in chimpanzees. Curr Biol 17:1704-1707. https://doi.org/10.1016/j.cub.2007.08.059

Brosnan SF, Schiff HC, de Waal FBM (2005) Tolerance for inequity may increase with social closeness in chimpanzees. Proc R Soc B Biol Sci 272:253-258. https://doi.org/10.1098/rspb.2004.2947

Brosnan SF, Talbot CF, Ahlgren M, et al (2010) Mechanisms underlying responses to inequitable outcomes in chimpanzees, Pan troglodytes. Anim Behav 79:1229-1237. https://doi.org/10.1016/j.anbehav.2010.02.019

Brosnan SF, Wilson BJ, Beran MJ (2012b) Old World monkeys are more similar to humans than New World monkeys when playing a coordination game. Proc R Soc B Biol Sci 279:1522-1530. https://doi.org/10.1098/rspb.2011.1781

Bshary R, Grutter AS (2002) Asymmetric cheating opportunities and partner control in a cleaner fish mutualism. Anim Behav 63:547555. https://doi.org/10.1006/anbe.2001.1937

Burnett CM, Kogan V (2015) When does ballot language influence voter choices? Evidence from a survey experiment. Polit Commun 32:109-126. https://doi.org/10.1080/10584609.2014.894160

Bütler M, Maréchal MA (2007) Framing effects in political decision making: Evidence from a natural voting experiment. Social Science Research Network, Rochester, NY

Cadario R, Chandon P (2019) Which healthy eating nudges work best? A meta-analysis of field experiments. Mark Sci. https://doi.org/10.1287/mksc.2018.1128

Camerer CF (2003) Behavioral game theory: Experiments in strategic interaction. Princeton University Press

Camerer CF (1998) Bounded rationality in individual decision making. Exp Econ 1:163-183. https://doi.org/10.1023/A:1009944326196

Caraco T (1981) Energy budgets, risk and foraging preferences in darkeyed juncos (Junco hyemalis). Behav Ecol Sociobiol 8:213-217

Casey AH, Silberberg A, Paukner A, Suomi SJ (2013) Defining reward value by cross-modal scaling. Anim Cogn 17:177-183.

https://doi.org/10.1007/s10071-013-0650-y

Central Policy Review Staff (1971) Concorde. UK 
Chernev A, Böckenholt U, Goodman J (2015) Choice overload: A conceptual review and meta-analysis. J Consum Psychol 25:333358. https://doi.org/10.1016/j.jcps.2014.08.002

Cho K, Barnes CM, Guanara CL (2017) Sleepy punishers are harsh punishers: Daylight saving time and legal sentences. Psychol Sci 28:242-247. https://doi.org/10.1177/0956797616678437

Chrysikou EG, Weisberg RW (2005) Following the wrong footsteps: Fixation effects of pictorial examples in a design problem-solving task. J Exp Psychol Learn Mem Cogn 31:1134-1148. https://doi.org/10.1037/0278-7393.31.5.1134

Cohen PM, Santos LR (2016) Capuchins (Cebus apella) fail to show an asymmetric dominance effect. Anim Cogn 1-15. https://doi.org/10.1007/s10071-016-1055-5

Cosmides L, Tooby J (1992) Cognitive adaptations for social exchange. In: Barkow J, Cosmides L, Tooby J (eds) The Adapted Mind: Evolutionary Psychology and the Generation of Culture. Oxford University Press, pp 163-228

Crooks NM, McNeil NM (2009) Increased practice with "set" problems hinders performance on the water jar task. Proc 31st Annu Conf Cogn Sci Soc 31:643-648

Danziger S, Levav J, Avnaim-Pesso L (2011) Extraneous factors in judicial decisions. Proc Natl Acad Sci U S A 108:6889-6892. https://doi.org/10.1073/pnas.1018033108

Dawkins R, Brockmann HJ (1980) Do digger wasps commit the concorde fallacy? Anim Behav 28:892-896. https://doi.org/10.1016/S00033472(80)80149-7

De Lillo C, Spinozzi G, Truppa V, Naylor DM (2005) A comparative analysis of global and local processing of hierarchical visual stimuli in young children (Homo sapiens) and monkeys (Cebus apella). J Comp Psychol 119:155-165. https://doi.org/10.1037/07357036.119.2.155

De Petrillo F, Rosati AG (2019) Ecological rationality: convergent decisionmaking in apes and capuchins. Behav Processes. https://doi.org/10.1016/j.beproc.2019.05.010

Dener E, Kacelnik A, Shemesh H (2016) Pea Plants Show Risk Sensitivity. Curr Biol 26:1763-1767. https://doi.org/10.1016/j.cub.2016.05.008

Drayton LA, Brosnan SF, Carrigan J, Stoinski TS (2013) Endowment effects in gorillas (Gorilla gorilla). J Comp Psychol 127:365-369. https://doi.org/10.1037/a0031902

Dugatkin LA (1997) Cooperation among animals: An evolutionary perspective. Oxford University Press, New York 
Duncker K (1945) On problem-solving. Psychol Monogr 58:i-113. https://doi.org/10.1037/h0093599

Egan Brad LC, Lakshminarayanan VR, Jordan MR, et al (2016) The evolution and development of peak-end effects for past and prospective experiences. J Neurosci Psychol Econ 9:1-13. https://doi.org/10.1037/npe0000048

Egan LC, Bloom P, Santos LR (2010) Choice-induced preferences in the absence of choice: Evidence from a blind two choice paradigm with young children and capuchin monkeys. J Exp Soc Psychol 46:204207. https://doi.org/10.1016/j.jesp.2009.08.014

Egan LC, Santos LR, Bloom P (2007) The origins of cognitive dissonance: Evidence from children and monkeys. Psychol Sci 18:978-983. https://doi.org/10.1111/j.1467-9280.2007.02012.x

ErEl H, Meiran N (2011) Mindset changes lead to drastic impairments in rule finding. Cognition 119:149-165. https://doi.org/10.1016/j.cognition.2011.01.002

Eren O, Mocan N (2016) Emotional judges and unlucky juveniles. National Bureau of Economic Research, Cambridge, MA

Ereshefsky M (2007) Psychological categories as homologies: Lessons from ethology. Biol Philos 22:659-674. https://doi.org/10.1007/s10539-0079091-9

Fagot J, Tomonaga M (1999) Global and local processing in humans (Homo sapiens) and chimpanzees (Pan troglodytes): Use of a visual search task with compound stimuli. J Comp Psychol 113:3-12. https://doi.org/10.1037/0735-7036.113.1.3

Flemming TM, Jones OD, Mayo L, et al (2012) The endowment effect in orangutans. Int J Comp Psychol 25:285-298

Gigerenzer G, Brighton H (2009) Homo heuristicus: Why biased minds make better inferences. Top Cogn Sci 1:107-143. https://doi.org/10.1111/j.1756-8765.2008.01006.x

Gigerenzer G, Goldstein DG (1996) Reasoning the fast and frugal way: Models of bounded rationality. Psychol Rev 103:650-669

Gigerenzer G, Selten R (eds) (2001) Bounded rationality: The adaptive toolbox. MIT Press

Gigerenzer G, Todd PM (1999) Simple heuristics that make us smart. Oxford University Press

Hanks AS, Just DR, Smith LE, Wansink B (2012) Healthy convenience: Nudging students toward healthier choices in the lunchroom. J Public Health 34:370-376. https://doi.org/10.1093/pubmed/fds003 
Heilbronner SR, Rosati AG, Stevens JR, et al (2008) A fruit in the hand or two in the bush? Divergent risk preferences in chimpanzees and bonobos. Biol Lett 4:246-249. https://doi.org/10.1098/rsbl.2008.0081

Henrich J, Boyd R, Bowles S, et al (2001) In search of Homo economicus: Behavioral experiments in 15 small-scale societies. Am Econ Rev 91:73-78

Hönicke C, Bliss P, Moritz RFA (2015) Effect of density on traffic and velocity on trunk trails of Formica pratensis. Sci Nat 102:17. https://doi.org/10.1007/s00114-015-1267-6

Jensen K, Tomasello M, Call J (2007) Chimpanzees are rational maximizers in an ultimatum game. Science 318:107-109. https://doi.org/10.1126/science.1145850

Johnson EJ, Goldstein DG (2004) Defaults and donation decisions. Transplantation 78:1713. https://doi.org/10.1097/01.TP.0000149788.10382.B2

Jones OD, Brosnan SF (2008) Law, biology, and property: A new theory of the endowment effect. William Mary Law Rev 49:1935-1990

Kacelnik A (2006) Meanings of rationality. In: Hurley S, Nudds M (eds) Rational animals? Oxford University Press, pp 87-106

Kahneman D (2011) Thinking, fast and slow. Farrar, Straus and Giroux

Kahneman D, Knetsch JL, Thaler RH (1991) Anomalies: The endowment effect, loss aversion, and status quo bias. J Econ Perspect 5:193-206. https://doi.org/10.1257/jep.5.1.193

Kahneman D, Knetsch JL, Thaler RH (2008) The endowment effect: Evidence of losses valued more than gains. In: Handbook of Experimental Economics Results. Elsevier, pp 939-948

Kahneman D, Slovic P, Tversky A (1982) Judgment under uncertainty: Heuristics and biases. Cambridge University Press

Kahneman D, Tversky A (1979) Prospect theory: An analysis of decision under risk. Econometrica 47:263-292

Kaiser I, Jensen K, Call J, Tomasello M (2012) Theft in an ultimatum game: Chimpanzees and bonobos are insensitive to unfairness. Biol Lett 8:942-945. https://doi.org/10.1098/rsbl.2012.0519

Kanngiesser P, Santos LR, Hood BM, Call J (2011) The limits of endowment effects in great apes (Pan paniscus, Pan troglodytes, Gorilla gorilla, Pongo pygmaeus). J Comp Psychol 125:436-445. https://doi.org/10.1037/a0024516

Knetsch JL (2000) The endowment effect and evidence of nonreversible indifference curves. In: Kahneman D, Tversky A (eds) Choices, 

179

1218

1219

1220

1221

1222

1223

1224

1225

1226

1227

1228

1229

1230

1231

1232

1233

1234

1235

1236

1237

1238

1239

1240

1241

1242

1243

1244

1245

1246

1247

1248

1249

1250

1251

1252

1253

1254

Lakshminarayanan VR, Chen MK, Santos LR (2011) The evolution of decision-making under risk: Framing effects in monkey risk preferences. J Exp Soc Psychol 47:689-693. https://doi.org/10.1016/j.jesp.2010.12.011

Lakshminaryanan V, Keith Chen M, Santos LR (2008) Endowment effect in capuchin monkeys. Philos Trans R Soc B Biol Sci 363:3837-3844. https://doi.org/10.1098/rstb.2008.0149

Laland KN, Galef BG (2009) The question of animal culture. Harvard University Press

Lorenz KZ (1958) The evolution of behavior. Sci Am 199:67-78. https://doi.org/10.1038/scientificamerican1258-67

Luchins AS (1942) Mechanization in problem solving: The effect of Einstellung. Psychol Monogr 54:1-95

Luchins AS, Luchins EH (1950) New experimental attempts at preventing mechanization in problem solving. J Gen Psychol 42:279-297. https://doi.org/10.1080/00221309.1950.9920160

Macaskill AC, Hackenberg TD (2012) The sunk cost effect with pigeons: Some determinants of decisions about persistence. J Exp Anal Behav 97:85-100. https://doi.org/10.1901/jeab.2012.97-85

MacLean EL, Merritt DJ, Brannon EM (2008) Social complexity predicts transitive reasoning in prosimian primates. Anim Behav 76:479486. https://doi.org/10.1016/j.anbehav.2008.01.025

Magalhães P, White KG (2016) The sunk cost effect across species: A review of persistence in a course of action due to prior investment. J Exp Anal Behav 105:339-361. https://doi.org/10.1002/jeab.202

Magalhães P, White KG, Stewart T, et al (2012) Suboptimal choice in nonhuman animals: Rats commit the sunk cost error. Learn Behav 40:195-206. https://doi.org/10.3758/s13420-011-0055-1

ManyPrimates, Altschul D, Beran MJ, et al (2019) Collaborative open science as a way to reproducibility and new insights in primate cognition research. Jpn Psychol Rev 62:205-220

Marsh B, Kacelnik A (2002) Framing effects and risky decisions in starlings. Proc Natl Acad Sci U S A 99:3352-3355. https://doi.org/10.1073/pnas.042491999

Melis AP, Hare B, Tomasello M (2006a) Chimpanzees recruit the best collaborators. Science 311:1297-1300. https://doi.org/10.1126/science.1123007 
1282

1283

1284

1285

1286

1287

1288

1289

1290

1291

1292

1293

1294

1295

Melis AP, Hare B, Tomasello M (2006b) Engineering cooperation in chimpanzees: Tolerance constraints on cooperation. Anim Behav 72:275-286. https://doi.org/10.1016/j.anbehav.2005.09.018

Navarro AD, Fantino E (2005) The sunk cost effect in pigeons and humans. J Exp Anal Behav 83:1-13. https://doi.org/10.1901/jeab.2005.21-04

Nielsen M, Haun D (2016) Why developmental psychology is incomplete without comparative and cross-cultural perspectives. Philos Trans R Soc B Biol Sci 371:. https://doi.org/10.1098/rstb.2015.0071

Oberliessen L, Kalenscher T (2019) Social and Non-social Mechanisms of Inequity Aversion in Non-human Animals. Front Behav Neurosci 13:. https://doi.org/10.3389/fnbeh.2019.00133

Paglieri F, Focaroli V, Bramlett J, et al (2013) The hybrid delay task: Can capuchin monkeys (Cebus apella) sustain a delay after an initial choice to do so? Behav Processes 94:45-54. https://doi.org/10.1016/j.beproc.2012.12.002

Parrish AE, Afrifa E, Beran MJ (2018) Exploring decoy effects on computerized task preferences in rhesus monkeys (Macaca mulatta). Anim Behav Cogn 5:1-19. https://doi.org/10.26451/abc.05.02.06.2018

Parrish AE, Brosnan SF, Wilson BJ, Beran MJ (2014) Differential responding by rhesus monkeys (Macaca mulatta) and humans (Homo sapiens) to variable outcomes in the Assurance Game. Anim Behav Cogn 1:215. https://doi.org/10.12966/abc.08.01.2014

Parrish AE, Evans TA, Beran MJ (2015) Rhesus macaques (Macaca mulatta) exhibit the decoy effect in a perceptual discrimination task. Atten Percept Psychophys 77:1715-1725. https://doi.org/10.3758/s13414015-0885-6

Pope SM, Fagot J, Meguerditchian A, et al (2019) Optional-switch cognitive flexibility in primates: Chimpanzees' (Pan troglodytes) intermediate susceptibility to cognitive set. J Comp Psychol. https://doi.org/10.1037/com0000194

Pope SM, Fagot J, Meguerditchian A, et al (2018) Enhanced cognitive flexibility in the seminomadic Himba. J Cross-Cult Psychol 50:4762. https://doi.org/10.1177/0022022118806581

Pope SM, Meguerditchian A, Hopkins WD, Fagot J (2015) Baboons (Papio papio), but not humans, break cognitive set in a visuomotor task. Anim Cogn 18:1339-1346. https://doi.org/10.1007/s10071-015-0904-y

Prétôt L, Bshary R, Brosnan SF (2016a) Comparing species decisions in a dichotomous choice task: Adjusting task parameters improves performance in monkeys. Anim Cogn 19:1-16. https://doi.org/10.1007/s10071-016-0981-6 
Prétôt L, Bshary R, Brosnan SF (2016b) Factors influencing the different performance of fish and primates on a dichotomous choice task. Anim Behav 119:189-199. https://doi.org/10.1016/j.anbehav.2016.06.023

Proctor D, Williamson RA, de Waal FBM, Brosnan SF (2013) Chimpanzees play the ultimatum game. Proc Natl Acad Sci 110:2070-2075. https://doi.org/10.1073/pnas.1220806110

Rajecki DW, Flanery RC (2013) Social conflict and dominance in children: A case for a primate homology. In: Lamb ME, Brown AL (eds) Advances in Developmental Psychology. Psychology Press, pp 87129

Redelmeier DA, Katz J, Kahneman D (2003) Memories of colonoscopy: A randomized trial. Pain 104:187-194. https://doi.org/10.1016/S03043959(03)00003-4

Rendall D, Di Fiore A (2007) Homoplasy, homology, and the perceived special status of behavior in evolution. J Hum Evol 52:504-521. https://doi.org/10.1016/j.jhevol.2006.11.014

Rosati AG, Stevens JR (2009) Rational decisions: The adaptive nature of context-dependent choice. In: Watanabe S, Blaisdell AP, Huber L, Young A (eds) Rational animals, irrational humans. Keio University Press

Ruscio AM, Amabile TM (1999) Effects of instructional style on problemsolving creativity. Creat Res J 12:251-266. https://doi.org/10.1207/s15326934crj1204_3

Salwiczek LH, Prétôt L, Demarta L, et al (2012) Adult cleaner wrasse outperform capuchin monkeys, chimpanzees and orang-utans in a complex foraging task derived from cleaner - client reef fish cooperation. PLoS ONE 7:e49068. https://doi.org/10.1371/journal.pone.0049068

Sánchez-Amaro A, Altınok N, Heintz C, Call J (2019) Disentangling great apes' decoy-effect bias in a food choice task. Anim Behav Cogn 6:213-222

Santos LR, Chen MK (2009) The evolution of rational and irrational economic behavior: Evidence and insight from a non-human primate species. In: Glimcher PW, Camerer CF, Fehr E, Poldrack RA (eds) Neuroeconomics: Decision making and the brain. Academic Press, pp 81-93

Santos LR, Rosati AG (2015) The evolutionary roots of human decision making. Annu Rev Psychol 66:321-347. https://doi.org/10.1146/annurev-psych-010814-015310

Sanz CM, Call J, Boesch C (2013) Tool use in animals: Cognition and ecology. Cambridge University Press 
Scheibehenne B, Greifeneder R, Todd PM (2010) Can there ever be too many options? A meta-analytic review of choice overload. J Consum Res 37:409-425. https://doi.org/10.1086/651235

Schwartz LP, Silberberg A, Casey AH, et al (2016) Scaling reward value with demand curves versus preference tests. Anim Cogn 19:631641. https://doi.org/10.1007/s10071-016-0967-4

Shafir S, Waite TA, Smith BH (2002) Context-dependent violations of rational choice in honeybees (Apis mellifera) and gray jays (Perisoreus canadensis). Behav Ecol Sociobiol 51:180-187. https://doi.org/10.1007/s00265-001-0420-8

Silberberg A, Parker S, Allouch C, et al (2013) Human risky choice in a repeated-gambles procedure: An up-linkage replication of Lakshminarayanan, Chen and Santos (2011). Anim Cogn 16:907914. https://doi.org/10.1007/s10071-013-0623-1

Smith MF, Watzek J, Brosnan SF (2018) The importance of a truly comparative methodology for comparative psychology. Int J Comp Psychol 31:

Smith P, Silberberg A (2010) Rational maximizing by humans (Homo sapiens) in an ultimatum game. Anim Cogn 13:671-677. https://doi.org/10.1007/s10071-010-0310-4

Spinozzi G, De Lillo C, Truppa V (2003) Global and local processing of hierarchical visual stimuli in tufted capuchin monkeys (Cebus apella). J Comp Psychol 117:15-23. https://doi.org/10.1037/07357036.117.1.15

Star JR, Seifert C (2006) The development of flexibility in equation solving. Contemp Educ Psychol 31:280-300. https://doi.org/10.1016/j.cedpsych.2005.08.001

Staw BM, Fox FV (1977) Escalation: The determinants of commitment to a chosen course of action. Hum Relat 30:431-450. https://doi.org/10.1177/001872677703000503

Staw BM, Hoàng H (1995) Sunk costs in the NBA: Why draft order affects playing time and survival in professional basketball. Adm Sci Q 40:474-494. https://doi.org/10.2307/2393794

Staw BM, Ross J (1989) Understanding behavior in escalation situations. Science 246:216-220. https://doi.org/10.1126/science.246.4927.216

Stevens JR (2012) Rational decision making in primates: the bounded and the ecological. In: Platt ML, Ghazanfar AA (eds) Primate Neuroethology. Oxford University Press, Oxford, pp 98-116

Stevens JR, Hallinan EV, Hauser MD (2005a) The ecology and evolution of patience in two New World monkeys. Biol Lett 1:223-226. https://doi.org/10.1098/rsbl.2004.0285 
Stevens JR, Rosati AG, Ross KR, Hauser MD (2005b) Will travel for food: Spatial discounting in two New World monkeys. Curr Biol 15:18551860. https://doi.org/10.1016/j.cub.2005.09.016

Suchak M, Eppley TM, Campbell MW, de Waal FBM (2014) Ape duos and trios: Spontaneous cooperation with free partner choice in chimpanzees. PeerJ 2:e417. https://doi.org/10.7717/peerj.417

Suchak M, Watzek J, Quarles LF, de Waal FBM (2017) Novice chimpanzees cooperate successfully in the presence of experts, but may have limited understanding of the task. Anim Cogn 61:489. https://doi.org/10.1007/s10071-017-1142-2

Sweis BM, Abram SV, Schmidt BJ, et al (2018) Sensitivity to "sunk costs" in mice, rats, and humans. Science 361:178-181. https://doi.org/10.1126/science.aar8644

Sweller J, Mawer RF, Howe W (1982) Consequences of history-cued and means-end strategies in problem solving. Am J Psychol 95:455-483. https://doi.org/10.2307/1422136

Thaler RH (1980) Toward a positive theory of consumer choice. J Econ Behav Organ 1:39-60. https://doi.org/10.1016/0167-2681(80)90051-7

Thaler RH (1992) The winner's curse: Anomalies and paradoxes of economic life. Princeton University Press

Thaler RH (2016) Misbehaving: The Making of Behavioral Economics, 1 edition. W. W. Norton \& Company, New York, London

Thaler RH, Sunstein CR (2009) Nudge: Improving decisions about health, wealth, and happiness. Penguin Books

The Modelling Animal Decisions Group, Fawcett TW, Fallenstein B, et al (2014) The evolution of decision rules in complex environments. Trends Cogn Sci 18:153-161. https://doi.org/10.1016/j.tics.2013.12.012

Thomas C, Didierjean A (2016) Magicians fix your mind: How unlikely solutions block obvious ones. Cognition 154:169-173. https://doi.org/10.1016/j.cognition.2016.06.002

Tomasello M, Call J (2011) Methodological challenges in the study of primate cognition. Science 334:1227-1228. https://doi.org/10.1126/science.1213443

Tversky A, Kahneman D (1981) The framing of decisions and the psychology of choice. Science 211:453-458. https://doi.org/10.1126/science.7455683

von Neumann J, Morgenstern O (2007) Theory of games and economic behavior. Princeton University Press 
Watzek J, Brosnan SF (2018) (Ir)rational choices of humans, rhesus macaques, and capuchin monkeys in dynamic stochastic environments. Cognition 178:109-117. https://doi.org/10.1016/j.cognition.2018.05.019

Watzek J, Pope SM, Brosnan SF (2019) Capuchin and rhesus monkeys but not humans show cognitive flexibility in an optional-switch task. Sci Rep 9:1-10. https://doi.org/10.1038/s41598-019-49658-0

Watzek J, Smith MF, Brosnan SF (2018) Comparative economics: Using experimental economic paradigms to understand primate social decision-making. In: di Paolo LD, di Vincenzo F, De Petrillo F (eds) Evolution of Primate Social Cognition. Springer, pp 129-141

Weatherhead PJ (1979) Do savannah sparrows commit the concorde fallacy? Behav Ecol Sociobiol 5:373-381. https://doi.org/10.1007/BF00292525

West S, Jett SE, Beckman T, Vonk J (2010) The phylogenetic roots of cognitive dissonance. J Comp Psychol 124:425-432. https://doi.org/10.1037/a0019932

Williamson R, MacDonald B, Brosnan SF (2019) Considering the role of experience in the formation of behavioral biases from a developmental, cross-cultural, and evolutionary perspective. Anim Behav Cogn 6:179-193. https://doi.org/10.26451/abc.06.03.03.2019

Xu ER, Knight EJ, Kralik JD (2011) Rhesus monkeys lack a consistent peakend effect. Q J Exp Psychol 64:2301-2315. https://doi.org/10.1080/17470218.2011.591936

Zentall TR (2016) When humans and other animals behave irrationally. Comp Cogn Behav Rev 11:25-48. https://doi.org/10.3819/ccbr.2016.110002

Zentall TR (2019) What suboptimal choice tells us about the control of behavior. Comp Cogn Behav Rev 14:. https://doi.org/10.3819/ccbr.2019.140001

Zentall TR, Laude JR, Case JP, Daniels CW (2014) Less means more for pigeons but not always. Psychon Bull Rev 21:1623-1628. https://doi.org/10.3758/s13423-014-0626-1 